\title{
Association between genetic variants in the tumour necrosis factor/lymphotoxin alpha/lymphotoxin beta locus and primary Sjogrens syndrome in Scandinavian samples
}

\author{
Anne Isine Bolstad, Stephanie Le Hellard, Gudlaug Kristjansdottir, Lilian Vasaitis, \\ Marika Kvarnstrom, Christoffer Sjöwall, Svein Joar Auglaend Johnsen, Per Eriksson, \\ Roald Omdal, Johan G Brun, Marie Wahren-Herlenius, Elke Theander, \\ Ann-Christine Syvanen, Lars Ronnblom, Gunnel Nordmark and Roland Jonsson
}

\section{Linköping University Post Print}

N.B.: When citing this work, cite the original article.

Original Publication:

Anne Isine Bolstad, Stephanie Le Hellard, Gudlaug Kristjansdottir, Lilian Vasaitis, Marika Kvarnstrom, Christoffer Sjöwall, Svein Joar Auglaend Johnsen, Per Eriksson, Roald Omdal, Johan G Brun, Marie Wahren-Herlenius, Elke Theander, Ann-Christine Syvanen, Lars Ronnblom, Gunnel Nordmark and Roland Jonsson, Association between genetic variants in the tumour necrosis factor/lymphotoxin alpha/lymphotoxin beta locus and primary Sjogrens syndrome in Scandinavian samples, 2012, Annals of the Rheumatic Diseases, (71), 6, 981988.

http://dx.doi.org/10.1136/annrheumdis-2011-200446

Copyright: BMJ Publishing Group

http://group.bmj.com/

Postprint available at: Linköping University Electronic Press

http://urn.kb.se/resolve?urn=urn:nbn:se:liu:diva-77855 


\section{Ann Rheum Dis}

Association between genetic variants in the tumor necrosis factor/ lymphotoxin alpha / lymphotoxin beta locus and primary Sjögren`s syndrome in Scandinavian samples

Anne Isine Bolstad ${ }^{1,2}$, Stephanie Le Hellard ${ }^{3,4}$, Gudlaug Kristjansdottir ${ }^{5}$, Lilian Vasaitis $^{5}$, Marika Kvarnström ${ }^{6}$, Christopher Sjöwall ${ }^{7}$, Svein Joar Auglænd Johnsen ${ }^{8}$, Per Eriksson ${ }^{7}$, Roald Omdal ${ }^{8}$, Johan G. Brun ${ }^{9}$, Marie Wahren-Herlenius ${ }^{6}$, Elke Theander $^{10}$, Ann-Christine Syvänen ${ }^{11}$, Lars Rönnblom ${ }^{5}$, Gunnel Nordmark ${ }^{5}$, Roland Jonsson $^{2}$

1 Department of Clinical Dentistry - Periodontics, University of Bergen, Bergen, Norway, 2 Broegelmann Research Laboratory, The Gade Institute, University of Bergen, Bergen, Norway, 3 Dr. Einar Martens' Research Group for Biological Psychiatry, Department of Clinical Medicine, University of Bergen, Bergen, Norway, 4 Center of Medical Genetics and Molecular Medicine, Haukeland University Hospital, Bergen, Norway, 5 Section of Rheumatology, Department of Medical Sciences, Uppsala University, Uppsala, Sweden, 6 Karolinska Institutet, Stockholm, Sweden, 7 Department of Rheumatology, Linköping University, Linköping, Sweden, 8 Stavanger University Hospital, Stavanger, Norway, 9 Department of Medicine, Section of Rheumatology, University of Bergen, Bergen, Norway, 10 Malmö University Hospital, Malmö, Sweden, 11 Molecular Medicine, Department of Medical Sciences, Uppsala University, Uppsala, Sweden.

\section{Correspondence to}

Anne Isine Bolstad, Department of Clinical Dentistry - Periodontics, University of Bergen, Aarstadveien 17, N-5009 Bergen, Norway. Tel: +47 55586646. E-mail: anne.bolstad@iko.uib.no . 


\section{ABSTRACT}

Objectives Lymphotoxin beta ( $L T B)$ has been found upregulated in salivary glands of patients with primary Sjögren’s syndrome (pSS). Also, an animal model of pSS showed ablation of the lymphoid organization and a marked improvement in salivary gland function upon blocking the LTB-receptor pathway. The aim of the present study was to investigate whether single nucleotide polymorphisms (SNPs) in the lymphotoxin alpha (LTA)/LTB/tumor necrosis factor $(T N F)$ gene clusters are associated with pSS.

Methods A total of 527 pSS patients and 532 controls participated in the study, all of Caucasian origin from Sweden and Norway. Fourteen SNP markers were genotyped and after quality control filtering, 12 SNPs were analysed for their association with pSS using single marker and haplotype tests, and corrected by permutation testing.

Results Nine markers showed significant association with pSS at the $\mathrm{p}=0.05$ level. Markers rs1800629 and rs909253 showed the strongest association (p-values=1.64E-11 and 4.42E-08, respectively, after correcting for sex and country of origin. When the analysis was conditioned for the effect of rs 1800629 , only the association to rs909253 remain nominally significant ( $\mathrm{p}$-value $=0.027$ ). In haplotype analyses the strongest effect was observed for the haplotype rs909253G_rs1800629A (p-value=9.14E-17). The associations were mainly due to anti-Ro/SSA and anti-La/SSB antibody positive pSS.

Conclusions A strong association was found between several SNPs in the $L T A / L T B / T N F \alpha$ locus and pSS, some of which lead to amino acid changes. Our data suggest a role for this locus in the development of pSS. Further studies are needed to examine if the genetic effect described in this study is independent of the known genetic association between the HLA and pSS.

Key words lymphotoxin, TNF, HLA, Sjögren's syndrome, SNP, autoimmune 
Primary Sjögren's syndrome (pSS) is an autoimmune chronic inflammatory disease affecting approximately $0.3 \%$ of the population $[1,2]$. The disease is typically diagnosed in women during their 5th decade of life. The main target organs in pSS are the exocrine glands, and the cardinal symptoms are dry eyes and dry mouth [2]. Systemic features that may be connected with the disease are fatigue, Raynauds phenomenon, cutaneous vasculitis, arthralgia, arthritis, lymphocytic colitis and celiac disease. Ectopic germinal center-like structures develop in salivary glands of about $20 \%$ of the patients, and is a possible predictor for development of malignant lymphoma in pSS [3]. About $70 \%$ and $40 \%$ of the patients, respectively, develop autoantibodies against the ribonucleotide proteins Ro/SSA and La/SSB [4]. In Caucasians, pSS is associated with the HLA DRB1*03, DQB1*02 and DQA1*05 alleles, and the association of HLA Class II markers with pSS may concern the anti-Ro/La response rather than the disease itself [5].

pSS is regarded as a multifactorial complex disease, where several genes are influencing the disease development in concert with immunological, hormonal and environmental factors $[6,7]$. Familial aggregation between pSS and other autoimmune diseases (AIDs) has been reported [8]. Most association studies based on single nucleotide polymorphism (SNP) analyses in pSS suffer from the low number of individuals enrolled [911], still polymorphisms in IRF5 and STAT4 have been convincingly associated and replicated as risk factors for pSS [12-14]. Gene expression studies, i.e. microarray, have demonstrated a strong interferon signature in pSS [15-17]. For instance, a very high upregulation of the lymphotoxin beta $(L T B)$ gene was identified in affected glands in pSS patients [15]. Blocking of the LT $\beta$ receptor (LT $\beta$ R) pathway with an immunoglobulin fusion protein (LT $\beta$ R-Ig) entailed increased secretion of saliva and reduced inflammation in pSS mouse model [18]. High LTB gene expression levels have later been reported in other AIDs, for instance in rheumatoid arthritis synovium [19].

The lymphotoxin system is part of the tumor necrosis factor (TNF) superfamily, and has an important role in the immune response and triggering of inflammation. Signalling through LT $\beta R$ is essential for lymphoid organogenesis and maintenance of tertiary lymphoid tissues. Genetic disruption of LT $\beta$ leads to disorganization of T and B cells in the spleen and absence of lymph nodes [20, 21]. Mice deprived of lymphotoxin alpha (LT $\alpha)$ also lack lymph nodes [22, 23].

A transmembrane heterotrimeric ligand, $\mathrm{LT} \alpha_{1} / \beta_{2}$ binds to the LT $\beta \mathrm{R}$, which defines the LT- LT $\beta$ R signalling axis [23-26]. Soluble $\mathrm{LT}_{3}$ has been associated with the 
proinflammatory cytokine milieu that contributes to synovitis in rheumatoid arthritis [27]. $\mathrm{LT} \alpha_{1} / \beta_{2}$ can be cleaved from the cell membrane and by that become converted into a soluble form that acts in concert with other proinflammatory cytokines to promote chronic tissue inflammation [27]. LT $\alpha, \mathrm{LT} \beta$ and also TNF $\alpha$ are encoded by genes clustered together on chromosome $6 \mathrm{p} 21.3$, with the close proximity of $12 \mathrm{~kb}$ within the HLA Class III region.

Taken together, these reports led us to hypothesize that genetic variants, which could influence the function or expression of $L T A, L T B$ and $T N F$, could be strong candidates as risk factors for pSS. The aim of the present study was therefore to examine if SNPs within this cluster of genes are associated with the presence of pSS in a large sample of Norwegian and Swedish cases and controls of Caucasian origin.

\section{METHODS}

\section{Study Cohorts and Phenotypes}

The study cohort is described in Table 1 . A total of 605 patients and 596 controls were included in the study. After genotype quality control where individuals with a genotype success rate of $<90 \%$ were removed, as well as individuals with non-Caucasian origin, 527 cases and 532 controls remained for analysis.

The patients were recruited from rheumatology clinics at Haukeland University Hospital, Bergen $(n=125)$ and Stavanger University Hospital $(n=68)$ in Norway, and from Stockholm $(n=59)$, Uppsala $(n=64)$, Malmö $(n=150)$ and Linköping $(n=61)$ University hospitals in Sweden. All patients were Caucasians and fulfilled the American European Consensus Criteria for Sjögren's syndrome [2]. Patients with secondary SS were excluded. Data on antibody profiles and extraglandular manifestations were obtained from medical records (Tables 1 and $\mathrm{S} 1$ ).

The controls were healthy blood donors recruited from the same geographical areas as the patients from Bergen $(n=142)$, Uppsala $(n=70)$ and Linköping $(n=18)$, and population based controls from Stockholm $(n=88)$ and Malmö $(n=143)$. In Stavanger the controls $(n=$ 71) were volunteers recruited as healthy control subjects for participation in a controlled pSS study. The study protocol was approved by the local Committees of Ethics in both Norway and Sweden, and the investigation has been conducted according to the principles expressed in the Declaration of Helsinki. All patients gave their written informed consent.

\section{Genotyping and Quality Control}


Fourteen tag-SNPs in the genomic region on chromosome $6 \mathrm{p} 21$ containing the $L T A, T N F$, $L T B$ and $L S T 1$ genes were selected and genotyped in the pSS patients and controls using the GoldenGate assay from Illumina Inc. (San Diego, CA, USA). The criteria for the tag-SNPs was an Illumina design score $>0.4$, minor allele frequency $>0.05$, a minimum of $60 \mathrm{bp}$ between SNPs (the limit for the GoldenGate assay) and $r^{2}>0.8$ With this design the 14 SNPs tagged 17/19 SNPs in the region $=89 \%$. Later, genotyping assays were developed for the ABI PRISMH 7900HT Sequence Detection System using TaqMan technology (Applied Biosystems, CA, USA), for the markers rs1800629 and rs361525. The ID and genomic positions of the genotyped SNPs according to the GRch37 (hg19) database UCSC (University of California, Santa Cruz) [28] are given in Table 2. Given the design of the study, the point was to cover the overall cluster of these genes to capture as much of the variation as possible in this region. Since there are no SNPs in the LTB region with a minor allele frequency > 0.01, we expanded the search to the surrounding region. Figure 1 illustrates the location of the genes $L T A, T N F, L T B$ and $L S T 1$ on chromosome 6p21. The positions of the SNPs genotyped in this study are indicated by their rs numbers.

The genotypes were filtered under the following criteria: DNA samples with genotyping call rate greater than 90\%; SNP call rate > 0.8, Hardy Weinberg Equilibrium pvalue $>0.001$, minor allele frequency $(\mathrm{MAF})>0.01$. After quality control filtering, $12 \mathrm{SNPs}$ and 1059 DNA samples remained in the study. The reproducibility was $100 \%$ for all SNPs as estimated from duplicated genotyping of $2.5 \%$ of the samples.

\section{Statistical analyses}

The SNPs were analysed for allelic association with logistic regression test (where the case versus control status was the outcome predicted by the genotypes) and genotypic association with a logistic regression on the 3 genotypes coded under an additive model $(d d=0, d D=1$ and $\mathrm{DD}=2$, where $\mathrm{D}$ is the minor allele). The result of the Single Marker Association and Logistic Regression Analysis (Allelic Test) of pSS patients and controls is shown in Table 2. The result of the Genotypic logistic regression is shown in Table 3. Analyses were performed using the SVS software (version 7.4.1, HelixTree Genetics Analysis Software, Golden Helix Inc., Bozeman, MT, USA, htpp://www.goldenhelix.com/SNP_Variation/HelixTree/index.html). For the haplotype analyses we used the EM method with a maximum iteration of 1,000 and a convergence tolerance of 0.0001 , and a minimum haplotype frequency of $1 \%$ as implemented in SVS. A logistic regression per haplotype was then calculated. 


\section{RESULTS}

Patients were examined for autoantibodies against ribonuclear proteins and for the extraglandular manifestations noted in Table 1 and S1. In all, $75.7 \%$ of the patients were antinuclear antibody (ANA) positive, $71.7 \%$ were anti-Ro/SSA positive and $45.1 \%$ antiLa/SSB antibody positive (Table 1). The most frequent extraglandular manifestation, hypergammaglobulinemia, was present in $50.5 \%$ of the patients (Table S1).

Fourteen Tag-SNPs covering the $L T A / L T B / T N F / L S T 1$ (LST 1; Leucocyte-specific transcript 1) locus were selected to capture most of the genetic variation in the region. After quality control filtering of the genotype data, a total of 1059 individuals and 12 SNPs remained for analysis. None of the SNPs tested showed pairwise LD r ${ }^{2}>0.75$ in the controls. At the allelic level, nine of the 12 SNPs showed significant associations with pSS using logistic regression analysis of the individual SNPs (Table 2). The SNP rs1800629 upstream of $T N F$ showed the lowest $P$-value in both the Norwegian and the Swedish cohorts, $P=2.30 \mathrm{E}$ 06 and $P=1.26 \mathrm{E}-05$, respectively. The strength of the association signal increased when the two cohorts were analysed together $(P$-value $=2.48 \mathrm{E}-10$ and odds ratio $(\mathrm{OR}) 2.00[95 \% \mathrm{CI}$ : $1.61-2.49$ ] for the minor allele A. The genotypic additive tests of the same SNP underscored the highly significant association of the markers with pSS in both populations (Table 3 ). Several other SNPs show strong association with pSS, notably rs909253 which reached a pvalue of $1.25 \mathrm{E}-07$ in the total sample (Table 2). In order to determine how many independent signals of association there were, we performed a conditional regression analysis, by using the rs1800629 genotypes as covariates. As shown in Table 3, only the association to rs909253 remains significant, which probably reflects that these two markers are in low linkage disequilibrium $\left(\mathrm{D}^{\prime}=0.89\right.$ and $\left.\mathrm{r}^{2}=0.39\right)$.

At the haplotype level, we performed trend regression analyses on 2- and 3- markers sliding windows (see Table 4). We observed several significant associations. Most of them, but not all, involved the 2 most associated SNPs rs909253 and rs1800629. Considering that after conditional regression for rs 1800629 the signal of association to rs909253 remained significant, we performed also haplotype association for these 2 markers. We observed a very significant association for the haplotype rs909253.G_rs1800629.A ( $P$-value $=9.14 \mathrm{E}-17)$ which is reflected by a frequency of this haplotype nearly doubled in cases compared to controls ( 0.29 versus 0.15 respectively) and a size effect of 2.14 (95\% CI: $1.72-2.65)$.

The SNP rs1800629 does not show strong LD $(\mathrm{r} 2=1)$ to other SNPs within 250kb, but rs909253 is in complete $\mathrm{LD}\left(\mathrm{D}^{\prime}=1, \mathrm{r}^{2}=1\right)$ with $\mathrm{rs} 1041981$, which introduces a missense polymorphism in exon 3 of the LTA gene (threonine to asparagine, T60N, referred to by some 
as $\mathrm{T} 26 \mathrm{~N})$, the same association would therefore be observed with rs 1041981 . We investigated also the LD between the associated SNPs and the HLA haplotypes, especially the B*0801/DRB1*0301/DQA1*0501/DQB1*0201(aka the COX haplotype, defined by the rs3129763.C_rs4639334.C haplotype [29]) which has been associated with pSS previously. At the single marker all pairwise comparisons between rs1800629 and rs909253 and the two COX haplotype markers show and $\mathrm{r}^{2}<0.33$. At the haplotype level, the global multi-allelic D' is 0.72. Only sixty five percent of the rs909253.G_rs1800629.A are also on the COX haplotype which means the rs909253.G_rs1800629.A is not an extension of the COX haplotype but is not completely independent of it. When we investigated the region for a marker that could be in LD with the rs909253.G_rs1800629.A haplotype, we identified a complete LD between this haplotype and the marker rs2857595, which is located $11.8 \mathrm{~kb}$ from LST1, which would need further investigation in later high density genotyping of the region.

Two of the other SNPs analysed in this study are located in exons, causing missense polymorphism: rs2229094 in exon 2 of LTA (cysteine to arginine), and rs2229092 in exon 3 of LTA (histidine to proline), only the SNP rs2229094 demonstrated a nominally significant association with pSS in the allelic and genotypic tests (Tables 2 and 3, and to autoantibodies Table 4), where the effect is associated to the major allele.

We stratified the patients with pSS into groups according to their status for the autoantibodies anti-Ro/SSA, anti-La/SSB or both. When we analysed the association between the SNPs in antibody positive patients $(\mathrm{n}=381)$ compared with controls $(\mathrm{n}=532)$ (Table 5), we found a stronger signal of association than in the complete set of patients for six of the SNPs with antibody positive pSS patients. The SNPs rs1800629, rs909253, rs915654 and rs2229094 gave the lowest $P$-values (P-values $=3.78 \mathrm{E}-18,1.14 \mathrm{E}-10,1.42 \mathrm{E}-08,2.37 \mathrm{E}-06$, respectively). When comparing the risk allele frequencies between the group of antibody positive patients $(n=381)$ with the risk allele frequencies in the group of antibody negative patients $(\mathrm{n}=138)$, a suggestive association with antibody positivity was observed for several of the SNPs (Table 5).

In addition, we tested the association of the eleven SNPs with extraglandular phenotypic characteristics such as hypergammaglobulinemia, hypothyroidism, arthritis, leucopenia and lymphoma (not shown). Several signals of association with nominal p-values $<0.05$ were observed, but none of them were stronger than the association with pSS or antibodies. 


\section{DISCUSSION}

In this study, SNP markers covering the $L T A, T N F, L T B$ and $L S T 1$ gene loci were examined for their association with pSS in Norwegian and Swedish samples of pSS patients. Significant associations were demonstrated with several of SNPs, and an especially strong association signal was obtained with the SNP rs1800629 ( $P$-value=2.48E-10), and for the haplotype rs909253.G_rs1800629.A $(P$-value $=9.14 \mathrm{E}-17)$.

The SNP rs1800629 (TNF $\alpha-308 \mathrm{G}>\mathrm{A})$ is a polymorphism of the TNF- $\alpha$ gene promoter that has been associated with TNF- $\alpha$ protein levels, inflammation and susceptibility to several AIDs [30-32], and also to non-Hodgkins lymphoma, specifically the subtype diffuse large Bcell lymphoma (DLBCL). This is of special interest since non-Hodgkins lymphoma is increased in the presence of autoimmune conditions such as Sjögren's syndrome [3, 33-36] [37] up to 16 fold according to Theander et al. [38]. Also, a large-scale consortial study provided evidence that the rs909253(LTA252A $>$ G)/rs1800629(TNF $\alpha-308 \mathrm{G}>\mathrm{A})$ haplotype containing the LTA/TNF variant alleles, which we found strongly associated in the present study to pSS, was strongly associated with DLBCL $\left(P=2.9 \times 10^{-8}\right)$ [36]. In addition, it was reported recently that the AA genotype of LTA804C>A, ie rs1041981 which causes a missense mutation in the LTA gene and is in LD with rs909253, and the GG genotype of receptor-interacting kinase 1 gene (RIPK1, rs2272990) may correlate with shorter time to progression in patients with DLBCL with a combination chemotherapy [39]. However, the SNP rs909253 was not associated with increased risk of lymphoma in our study, maybe due to the low number of lymphomas in our cohort and consequently, lack of power in our casecase analysis. Another possibility could be that they constitute different types of lymphomas. It should also be mentioned that though there are several reports of associations between SNP rs1800269 and several diseases and protein levels, direct functional consequences of the TNF$\alpha$ promoter polymorphism on a cellular level are at present not clear [40].Mutations in the TNF and LTA genes have been reported to be correlated with the outcome of patients during serious infections [41]. The SNP rs909253 was reported to enhance the transcriptional level of LTA and the plasma levels of LT $\alpha$ [41]. A strong association of this SNP with susceptibility to myocardial infarction has been reported [42], and an increased risk for lethal infections during treatment of childhood acute leukemia [41]. LT $\alpha$ was also expressed in atherosclerotic lesions in mice, and interestingly, loss of LT $\alpha$ reduced the size of those lesions with $62 \%$, whereas loss of TNF did not alter lesion development compared with wild-type mice [43]. This demonstrated a role for LT $\alpha$ in promoting lesion growth. 
Interestingly, the association between several of the twelve SNPs analyzed in the $L T A / L T B / T N F$ locus and pSS was almost entirely due to the antibody positive pSS patients. The SNPs most strongly associated with pSS in the whole cohort, rs1800629 and rs909253, showed an even higher association signal when only antibody-positive patients with pSS were compared with the controls $(P$-values=3.78E-18, OR=3.09 and1.14E-10, OR 1.90, respectively), despite a lower number of patients. It is noteworthy that the minor allele frequency among the antibody negative patients was similar to the controls $(0.19$ versus 0.20 for rs 1800629 , and 0.40 versus 0.37 for rs 909253 ), in contrast to the frequencies in antibodypositive patients (0.52 and 0.39). A stronger association between anti-SSA and anti-SSB antibody positive pSS patients and HLA-DRB $1 * 03$ compared with antibody negative patients has been described previously [5], and our present results confirm genetic differences between antibody-positive versus antibody-negative patients with pSS.

By linkage disequilibrium, the region tested in the present study encompasses also LST1. The specific function of LST1 is not known, although expression analysis and functional data suggest an immunomodulatory role with a strong inhibitory effect on lymphocyte proliferation [44]. The expression of $L S T 1$ was reported to be increased in rheumatoid-arthritis-affected blood and synovium, and associated with more severe inflammation in the synovium [19]. LST1 has been found significantly up-regulated in response to lipopolysaccharide, IFN- $\gamma$ and bacterial infection [44], and IFN- $\gamma$ and interferon induced genes have been found upregulated in pSS [15, 17].

Several genes encoding proteins involved in immune and inflammatory responses are located within the MHC Class III region. Unravelling the genes of a complex genetic disease is challenging [45], even more so in the genomic region of the MHC where the extended LD renders the interpretation of association difficult [29]. In the present study, the association observed would reflect a specific effect of genetic variant(s) on one or another gene in the cluster, but as some LD between this cluster and other HLA loci has been reported it is difficult to entangle this effect from potential long range effect of other variants in the MHC region. Association to several HLA loci, including $L T A / L T B / T N F$, and several AID is well documented and several studies have aimed at understanding the complexity of this region [46-48]. Several extended haplotypes in the regions have been associated to AIDs. In pSS, association reports to the HLA haplotypes, for instance with the COX haplotype, have been conflicting, and none has reported an effect as strong as the one we observe in the present study. In addition we found that the haplotype associated in this study is not in LD with the COX haplotype. The basis for this study was that in salivary glands of patients we observed a 
strong up-regulation of LTB, which was in agreement with further support for a role of LTB in pSS. Interestingly in a recent effort to understand the effect of different HLA haplotypes on the expression of genes located in the MHC region, Vandiedock et al. [45] showed an upregulation of TNF and LTA, and a down regulation of LTB in cell lines homozygous for the COX haplotype (Figure S1), thus in contradiction with the upregulation we observed in salivary glands of patients with pSS Further work is then warranted to understand the association between the present haplotype and pSS or other AID and their effect on the genes in the region.

Although AIDs share many genetic factors resulting in similarity of disease mechanisms, there is evidence that points towards genetic differences between them. The multiple genome wide association studies (GWAS) performed across AIDs have made it possible to study the homogeneity of genetic architecture across these diseases [49], and systematically identify allele-specific relationships. Interestingly, Sirota et al. used GWAS data to compare genetic variation profiles of six AIDs and five non-AIDs [50,51], they were able to differentiate clusters of AIDs where SNPs that make an individual susceptible to one class of AID, also protect from disease in another autoimmune class. In other words, they performed an AID classification by reverse association with SNP. Hopefully such approach will also add new information about the genetics of pSS in the future, though GWAS with large sample for pSS are still needed.

In conclusion, the present study provides strong support for the involvement of $L T A / L T B / T N F$ in $\mathrm{pSS}$, in particular anti-SSA and anti-SSB antibody positive pSS. Further high density genotyping, gene expression profiling or re-sequencing of the region is warranted in both patients and controls and in several tissues to better understand the complexity of this region.

\section{Acknowledgements}

We thank the patients and controls for their participation in the study. Genotyping by the Illumina Golden Gate assay was performed by the SNP Technology Platform at Uppsala University, Sweden (www.genotyping.se). We thank Per Lundmark and Tomas Axelsson for help with design of the genotyping assays, and Carla P. Fernandes and Marianne Eidsheim for technical assistance with the TaqMan assays. 


\section{Funding}

Western Norway Regional Health Authority. The Research Council of Norway. The Strategic

Research Program at Helse Bergen. The Broegelmann Foundation, University of Bergen.

Bergens forskningsstiftelse, University of Bergen. The Swedish Research Council. The

Stockholm County Council. The Göran Gustafsson Foundation. The Torsten and Ragnar

Söderberg Foundation. The King Gustaf the V:th 80-year Foundation. Anna-Greta Crafoord

Foundation. Malmö University Hospital Cancer Research Foundation. Vinnova,

Vårdalstiftelsen, The Swedish Foundation for Strategic Research, The Swedish Rheumatism Association, Invest in Sweden Agency, KK-stiftelsen.

The funders had no role in study design, data collection and analysis, decision to publish, or preparation of the manuscript.

Patient consent Obtained

Ethics approval The study protocol was approved by the local Committees of Ethics in both Norway and Sweden, and the investigation has been conducted according to the principles expressed in the Declaration of Helsinki. All patients gave their written informed consent.

\section{Competing Interests None declared}

\section{Licence for Publication}

The Corresponding Author has the right to grant on behalf of all authors and does grant on behalf of all authors, an exclusive licence (or non exclusive for government employees) on a worldwide basis to the BMJ Publishing Group Ltd to permit this article (if accepted) to be published in ARD and any other BMJPGL products and sublicences such use and exploit all subsidiary rights, as set out in our licence (http://group.bmj.com/products/journals/instructions-for-authors/licence-forms).

\section{REFERENCES}

1. Bowman SJ, Ibrahim GH, Holmes G et al. Estimating the prevalence among Caucasian women of primary Sjogren's syndrome in two general practices in Birmingham, UK. Scand J Rheumatol 2004;33:39-43. 
2. Vitali C, Bombardieri S, Jonsson R et al. Classification criteria for Sjogren's syndrome: a revised version of the European criteria proposed by the AmericanEuropean Consensus Group. Ann Rheum Dis 2002;61:554-558.

3. Theander E, Vasaitis L, Baecklund E et al. Lymphoid organisation in labial salivary gland biopsies is a possible predictor for the development of malignant lymphoma in primary Sjogren's syndrome. Annals of the rheumatic diseases 2011;70:1363-1368.

4. Gordon TP, Bolstad AI, Rischmueller M et al. Autoantibodies in primary Sjogren's syndrome: new insights into mechanisms of autoantibody diversification and disease pathogenesis. Autoimmunity 2001;34:123-132.

5. Bolstad AI, Wassmuth R, Haga HJ et al. HLA markers and clinical characteristics in Caucasians with primary Sjogren's syndrome. J Rheumatol 2001;28:1554-1562.

6. Bolstad AI, Jonsson R. Genetic aspects of Sjogren's syndrome. Arthritis Res 2002;4:353-359.

7. Jonsson R, Bolstad AI, Brokstad KA et al. Sjogren's syndrome--a plethora of clinical and immunological phenotypes with a complex genetic background. Ann N Y Acad Sci 2007;1108:433-447.

8. Reveille JD, Macleod MJ, Whittington K et al. Specific amino acid residues in the second hypervariable region of HLA- DQA1 and DQB1 chain genes promote the Ro (SS-A)/La (SS-B) autoantibody responses. J Immunol 1991;146:3871-3876.

9. Bolstad AI, Wargelius A, Nakken B et al. Fas and Fas ligand gene polymorphisms in primary Sjogren's syndrome. J Rheumatol 2000;27:2397-2405.

10. Harangi M, Kaminski WE, Fleck M et al. Homozygosity for the 168 His variant of the minor histocompatibility antigen HA-1 is associated with reduced risk of primary Sjogren's syndrome. Eur J Immunol 2005;35:305-317.

11. Nakken B, Jonsson R, Bolstad AI. Polymorphisms of the Ro52 gene associated with anti-Ro 52-kd autoantibodies in patients with primary Sjogren's syndrome. Arthritis Rheum 2001;44:638-646.

12. Miceli-Richard C, Comets E, Loiseau P et al. Association of an IRF5 gene functional polymorphism with Sjogren's syndrome. Arthritis Rheum 2007;56:3989-3994.

13. Korman BD, Alba MI, Le JM et al. Variant form of STAT4 is associated with primary Sjogren's syndrome. Genes Immun 2008;9:267-270.

14. Nordmark G, Kristjansdottir G, Theander E et al. Additive effects of the major risk alleles of IRF5 and STAT4 in primary Sjogren's syndrome. Genes Immun 2009;10:6876.

15. Hjelmervik TO, Petersen K, Jonassen I et al. Gene expression profiling of minor salivary glands clearly distinguishes primary Sjogren's syndrome patients from healthy control subjects. Arthritis Rheum 2005;52:1534-1544.

16. Emamian ES, Leon JM, Lessard CJ et al. Peripheral blood gene expression profiling in Sjogren's syndrome. Genes Immun 2009;10:285-296.

17. Gottenberg JE, Cagnard N, Lucchesi C et al. Activation of IFN pathways and plasmacytoid dendritic cell recruitment in target organs of primary Sjogren's syndrome. Proc Natl Acad Sci U S A 2006;103:2770-2775.

18. Gatumu MK, Skarstein K, Papandile A et al. Blockade of lymphotoxin-beta receptor signaling reduces aspects of Sjogren's syndrome in salivary glands of non-obese diabetic mice. Arthritis Res Ther 2009;11:R24.

19. O'Rourke KP, O'Donoghue G, Adams C et al. High levels of Lymphotoxin-Beta (LTBeta) gene expression in rheumatoid arthritis synovium: clinical and cytokine correlations. Rheumatol Int 2008;28:979-986. 
20. Rennert PD, Browning JL, Mebius R et al. Surface lymphotoxin alpha/beta complex is required for the development of peripheral lymphoid organs. J Exp Med 1996;184:1999-2006.

21. Vondenhoff MF, Greuter M, Goverse G et al. LTbetaR signaling induces cytokine expression and up-regulates lymphangiogenic factors in lymph node anlagen. $\mathbf{J}$ Immunol 2009;182:5439-5445.

22. Mebius RE. Organogenesis of lymphoid tissues. Nat Rev Immunol 2003;3:292-303.

23. Browning JL, Ngam-ek A, Lawton P et al. Lymphotoxin beta, a novel member of the TNF family that forms a heteromeric complex with lymphotoxin on the cell surface. Cell 1993;72:847-856.

24. Browning JL, Miatkowski K, Griffiths DA et al. Preparation and characterization of soluble recombinant heterotrimeric complexes of human lymphotoxins alpha and beta. J Biol Chem 1996;271:8618-8626.

25. Bossen $\mathrm{C}$, Ingold $\mathrm{K}$, Tardivel A et al. Interactions of tumor necrosis factor (TNF) and TNF receptor family members in the mouse and human. $\mathrm{J}$ Biol Chem 2006;281:13964-13971.

26. Browning JL. Inhibition of the lymphotoxin pathway as a therapy for autoimmune disease. Immunol Rev 2008;223:202-220.

27. Young J, Yu X, Wolslegel K et al. Lymphotoxin-alphabeta heterotrimers are cleaved by metalloproteinases and contribute to synovitis in rheumatoid arthritis. Cytokine 2010;51:78-86.

28. Rhead B, Karolchik D, Kuhn RM et al. The UCSC Genome Browser database: update 2010. Nucleic Acids Res 38:D613-619.

29. de Bakker PI, McVean G, Sabeti PC et al. A high-resolution HLA and SNP haplotype map for disease association studies in the extended human MHC. Nature genetics 2006;38:1166-1172.

30. Abraham LJ, Kroeger KM. Impact of the -308 TNF promoter polymorphism on the transcriptional regulation of the TNF gene: relevance to disease. J Leukoc Biol 1999;66:562-566.

31. Mira JP, Cariou A, Grall F et al. Association of TNF2, a TNF-alpha promoter polymorphism, with septic shock susceptibility and mortality: a multicenter study. JAMA : the journal of the American Medical Association 1999;282:561-568.

32. Wang B, Wang J, Zheng Y et al. A study of TNF-alpha-238 and -308 polymorphisms with different outcomes of persistent hepatitis B virus infection in China. Pathology 2010;42:674-680.

33. Abdou AM, Gao X, Cozen W et al. Human leukocyte antigen (HLA) A1-B8-DR3 (8.1) haplotype, tumor necrosis factor (TNF) G-308A, and risk of non-Hodgkin lymphoma. Leukemia 2010;24:1055-1058.

34. Wang SS, Cozen W, Cerhan JR et al. Immune mechanisms in non-Hodgkin lymphoma: joint effects of the TNF G308A and IL10 T3575A polymorphisms with non-Hodgkin lymphoma risk factors. Cancer Res 2007;67:5042-5054.

35. Fernberg P, Chang ET, Duvefelt K et al. Genetic variation in chromosomal translocation breakpoint and immune function genes and risk of non-Hodgkin lymphoma. Cancer Causes Control 2010;21:759-769.

36. Skibola CF, Bracci PM, Nieters A et al. Tumor necrosis factor (TNF) and lymphotoxin-alpha (LTA) polymorphisms and risk of non-Hodgkin lymphoma in the InterLymph Consortium. Am J Epidemiol 2010;171:267-276.

37. Rothman N, Skibola CF, Wang SS et al. Genetic variation in TNF and IL10 and risk of non-Hodgkin lymphoma: a report from the InterLymph Consortium. Lancet Oncol 2006;7:27-38. 
38. Theander E, Henriksson G, Ljungberg O et al. Lymphoma and other malignancies in primary Sjogren's syndrome: a cohort study on cancer incidence and lymphoma predictors. Ann Rheum Dis 2006;65:796-803.

39. Chae YS, Kim JG, Sohn SK et al. Lymphotoxin alfa and receptor-interacting protein kinase 1 gene polymorphisms may correlate with prognosis in patients with diffuse large B cell lymphoma treated with R-CHOP. Cancer Chemother Pharmacol 65:571577.

40. Mekinian A, Tamouza R, Pavy S et al. Functional study of TNF-alpha promoter polymorphisms : literature review and meta-analysis. Eur Cytokine Netw 2011;22:88102.

41. Kidas E, Moricke A, Beier R et al. Genetic polymorphisms of the lymphotoxin alpha gene are associated with increased risk for lethal infections during induction therapy for childhood acute leukemia: a case-control study. Int J Hematol 2009;89:584-591.

42. Ozaki K, Ohnishi Y, Iida A et al. Functional SNPs in the lymphotoxin-alpha gene that are associated with susceptibility to myocardial infarction. Nat Genet 2002;32:650654.

43. Schreyer SA, Vick CM, LeBoeuf RC. Loss of lymphotoxin-alpha but not tumor necrosis factor-alpha reduces atherosclerosis in mice. J Biol Chem 2002;277:1236412368.

44. Mulcahy H, O'Rourke KP, Adams C et al. LST1 and NCR3 expression in autoimmune inflammation and in response to IFN-gamma, LPS and microbial infection. Immunogenetics 2006;57:893-903.

45. Vandiedonck C, Taylor MS, Lockstone HE et al. Pervasive haplotypic variation in the spliceo-transcriptome of the human major histocompatibility complex. Genome research 2011;21:1042-1054.

46. Fernando MM, Stevens CR, Walsh EC et al. Defining the role of the MHC in autoimmunity: a review and pooled analysis. PLoS Genet 2008;4:e1000024.

47. McHugh NJ, Owen P, Cox B et al. MHC class II, tumour necrosis factor alpha, and lymphotoxin alpha gene haplotype associations with serological subsets of systemic lupus erythematosus. Ann Rheum Dis 2006;65:488-494.

48. Noble JA, Valdes AM, Lane JA et al. Linkage disequilibrium with predisposing DR3 haplotypes accounts for apparent effects of tumor necrosis factor and lymphotoxinalpha polymorphisms on type 1 diabetes susceptibility. Hum Immunol 2006;67:9991004.

49. Hindorff LA, Sethupathy P, Junkins HA et al. Potential etiologic and functional implications of genome-wide association loci for human diseases and traits. Proc Natl Acad Sci U S A 2009;106:9362-9367.

50. Schaub MA, Kaplow IM, Sirota M et al. A Classifier-based approach to identify genetic similarities between diseases. Bioinformatics 2009;25:i21-29.

51. Sirota M, Schaub MA, Batzoglou S et al. Autoimmune disease classification by inverse association with SNP alleles. PLoS Genet 2009;5:e1000792. 


\section{Figure legend.}

Figure 1. Region of association around the $L T A, T N F A, L T B$ and $L S T 1$ genes on chromosome 6p21, and LD plot of HapMap pSS data on the associated Class IV SNPs. The HapMap coordinates are numbered according to the GRch37 database (hg19) [28]. Exons are depicted as blue rectangles, while introns are depicted as blue horizontal lines. The markers can be identified by their rs numbers. The y-axis in the graph corresponds to the negative $\log 10$ of the $P$-values for each marker in a test of association with pSS. The lower part of the figure illustrates the degree of correlation (LD) between pairs of markers which is indicated by the observed $\mathrm{r}^{2}$ value in the control sample (black/white scale or $\mathrm{r}^{2}$, with black is $r^{2}=1$, white is $r^{2}=0,100 \times r^{2}$ is displayed).

Figure S1. Haplotype-specific pattern of expression. Cell line transcription levels of the genes LTA, TNF, LTB and LST1 of three different cell lines; PGF (HLA-A3-B7-Cw7-DR15, pink), COX (HLA-A1-B8-Cw7-DR3, yellow) and QBL (HLA-A26-B18-Cw5-DR3-DQ2, purple). Bars corresponding to the genes on the minus strand are displayed leftward, those for the plus strand rightward. (Modified from Vandiedonck et al. [45]). 
Table 1 Characterization of the study cohorts.

\begin{tabular}{|c|c|c|c|c|c|c|c|c|}
\hline \multirow[t]{2}{*}{ Category } & \multicolumn{2}{|c|}{ Cases (pSS patients) } & \multirow[b]{2}{*}{ Total sample } & \multirow[b]{2}{*}{$P$-value ${ }^{a}$} & \multicolumn{2}{|c|}{ Healthy controls } & \multirow[b]{2}{*}{ Total sample } & \multirow[b]{2}{*}{$P$-value ${ }^{a}$} \\
\hline & Norway & Sweden & & & Norway & Sweden & & \\
\hline Subjects & 193 & 334 & 527 & & 213 & 319 & 532 & \\
\hline Females (\%) & $178(90.8)$ & $309(92.5)$ & $487(92.4)$ & 1.00 & $193(90.6)$ & $292(91.5)$ & 485 (91.2) & 0.76 \\
\hline Age $( \pm S D)^{b}$ & $57.4(11.8)$ & $58.2(14.0)$ & $57.9(13.2)$ & 0.66 & $49.3(13.6)$ & $57.7(11.4)$ & $54.2(13.0)$ & $<0.0001$ \\
\hline Age females $( \pm S D)^{b}$ & $57.3(11.8)$ & $58.2(14.0)$ & $57.9(13.2)$ & & $48.9(13.7)$ & $57.5(11.2)$ & $53.8(13.0)$ & \\
\hline Age males $( \pm S D)^{b}$ & $58.7(11.5)$ & $57.9(15.0)$ & $58.2(13.6)$ & & $56.7(11.6)$ & $59.3(13.0)$ & $58.5(12.4)$ & \\
\hline ANA (\%) & $143(74.1)$ & $256(76.6)$ & $399(75.7)$ & 0.53 & & & & \\
\hline Anti-Ro/SSA (\%) & $132(71.4)$ & $240(71.9)$ & $372(71.7)$ & 0.43 & & & & \\
\hline Anti-La/SSB (\%) & $82(44.3)$ & $152(45.5)$ & $234(45.1)$ & 0.52 & & & & \\
\hline Anti-Ro/SSA- Anti-La/SSB (\%) & $138(74.6)$ & $243(72.8)$ & $381(73.4)$ & 0.76 & & & & \\
\hline
\end{tabular}

${ }^{\mathrm{a}}$ Frequencies compared by Fisher's exact test. ${ }^{\mathrm{b}} \mathrm{Age}$ at inclusion in the study. Data were missing for 135 controls (47 Norwegian and 88 Swedish controls). ANA, anti-nuclear antibodies. Anti-Ro/SSA and anti-La/SSB, ribonucleproteins. 
Table 2 Allelic association of individual SNPs by Logistic Regression in pSS patients and controls.

\begin{tabular}{|c|c|c|c|c|c|c|c|c|c|}
\hline & Marker & $\begin{array}{l}\text { Loc bp } \\
\text { UCSC }^{\mathrm{a}}\end{array}$ & Loc gene & & $\begin{array}{r}r \text { allele } \\
\text { Cases }\end{array}$ & Ctr & OR $(95 \% \mathrm{Cl})$ & Major allele & $\begin{array}{l}\text { Regression } \\
P \text {-value }\end{array}$ \\
\hline Total & rs915654 & 31538497 & 1379 basis & $\mathrm{T}$ & 0.25 & 0.32 & $0.69(0.57-0.83)$ & $A$ & 1.13E-04 \\
\hline Norway & & & upstream & $\mathrm{T}$ & 0.27 & 0.36 & $0.67(0.50-0.91)$ & $A$ & 9.32E-03 \\
\hline Sweden & & & of $L T A$ & $\mathrm{~T}$ & 0.23 & 0.30 & $0.71(0,55-0.91)$ & A & 5.86E-03 \\
\hline Total & rs2844482 & 31539767 & 109 basis & $A$ & 0.11 & 0.15 & $0.71(0.55-0.91)$ & $\mathrm{G}$ & $6.92 \mathrm{E}-03$ \\
\hline Norway & & & upstream & A & 0.13 & 0.17 & $0.72(0.49-1.07)$ & $\mathrm{G}$ & $1.03 \mathrm{E}-01$ \\
\hline Sweden & & & of $L T A$ & A & 0.10 & 0.14 & $0.70(0.50-0.98)$ & $\mathrm{G}$ & 3.85E-02 \\
\hline Total & rs2239704 & 31540141 & Intron 1/ & $A$ & 0.32 & 0.37 & $0.80(0.66-0.96)$ & $\mathrm{C}$ & 1.42E-02 \\
\hline Norway & & & 5'-UTR of & $A$ & 0.31 & 0.36 & $0.79(0.59-1.06)$ & $\mathrm{C}$ & $1.11 \mathrm{E}-01$ \\
\hline Sweden & & & LTA & A & 0.33 & 0.38 & $0.80(0.63-1.01)$ & C & 5.71E-02 \\
\hline Total & rs909253 & 31540313 & LTA intron 1 & $\mathrm{G}$ & 0.49 & 0.37 & $1.59(1.34-1.89)$ & $A$ & $1,25 \mathrm{E}-07$ \\
\hline Norway & & & & G & 0.49 & 0.38 & $1.58(1.20-2.09)$ & A & 1.27E-03 \\
\hline Sweden & & & & $\mathrm{G}$ & 0.48 & 0.37 & $1.61(1.29-2.00)$ & $A$ & 2.52E-05 \\
\hline Total & rs2229094 & 31540556 & LTA exon 2 & $\mathrm{G}$ & 0.19 & 0.25 & $0.69(0.56-0.85)$ & $A$ & $4.15 \mathrm{E}-04$ \\
\hline Norway & & & $(C>R)$ & $\mathrm{G}$ & 0.19 & 0.25 & $0.71(0.51-0.99)$ & A & 4.15E-02 \\
\hline Sweden & & & & $\mathrm{G}$ & 0.18 & 0.25 & $0.68(0.52-0.89)$ & $A$ & 4.13E-03 \\
\hline Total & rs2229092 & 31540757 & LTA exon 3 & $\mathrm{C}$ & 0.05 & 0.06 & $0.80(0.55-1.16)$ & $A$ & $2.40 \mathrm{E}-01$ \\
\hline Norway & & & $(\mathrm{H}>\mathrm{P})$ & $\mathrm{C}$ & 0.07 & 0.09 & $0.82(0.49-1.37)$ & A & 4.52E-01 \\
\hline Sweden & & & & $\mathrm{C}$ & 0.04 & 0.05 & $0.82(0.47-1.41)$ & A & 4.66E-01 \\
\hline Total & rs1799964 & 31542308 & 210 basis & $\mathrm{G}$ & 0.15 & 0.20 & $0.74(0.59-0.93)$ & $A$ & $9.60 \mathrm{E}-03$ \\
\hline Norway & & & downstream & $\mathrm{G}$ & 0.17 & 0.21 & $0.79(0.56-1.13)$ & A & 1.96E-01 \\
\hline Sweden & & & of $L T A$ & $\mathrm{G}$ & 0.14 & 0.19 & $0.72(0.53-0.96)$ & $A$ & 2.57E-02 \\
\hline Total & rs1800629 & 31543031 & 319 basis & $A$ & 0.34 & 0.20 & $2.00(1.61-2.49)$ & $\mathrm{G}$ & 2.48E-10 \\
\hline Norway & & & upstream of & A & 0.36 & 0.19 & $2.40(1.65-3.48)$ & $\mathrm{G}$ & $2.30 \mathrm{E}-06$ \\
\hline Sweden & & & TNF & A & 0.33 & 0.21 & $1.81(1.38-2.37)$ & $\mathrm{G}$ & 1.26E-05 \\
\hline Total & rs3093662 & 31544189 & TNFA & $\mathrm{G}$ & 0.04 & 0.05 & $0.83(0.55-1.25)$ & $A$ & 3.79E.01 \\
\hline Norway & & & intron 2 & G & 0.04 & 0.04 & $0.92(0.46-1.84)$ & A & 8.07E-01 \\
\hline Sweden & & & & $\mathrm{G}$ & 0.04 & 0.05 & $0.78(0.47-1.30)$ & $A$ & 3.44E.01 \\
\hline Total & rs769178 & 31547514 & 823 basis & $A$ & 0.05 & 0.06 & $0.98(0.66-1.43)$ & $\mathrm{C}$ & $9.04 \mathrm{E}-01$ \\
\hline Norway & & & downstream & A & 0.06 & 0.06 & $1.03(0.56-1.88)$ & $\mathrm{C}$ & $9.35 \mathrm{E}-01$ \\
\hline Sweden & & & of $L T B$ & A & 0.05 & 0.05 & $0.95(0.58-1.57)$ & C & $8.42 \mathrm{E}-01$ \\
\hline Total & rs2256965 & 31555130 & LST1 & A & 0.34 & 0.40 & $0.76(0.63-0.90)$ & $\mathrm{G}$ & $1.90 \mathrm{E}-03$ \\
\hline Norway & & & Intron 2 & A & 0.31 & 0.39 & $0.71(0.53-0.95)$ & $\mathrm{G}$ & 2.24E-02 \\
\hline Sweden & & & & A & 0.36 & 0.42 & $0.77(0.62-0.97)$ & $\mathrm{G}$ & 2.51E-02 \\
\hline Total & rs1052248 & 31556581 & 3'UTR & $\mathrm{T}$ & 0.20 & 0.25 & $0.76(0.61-0.93)$ & $A$ & 6.91E-03 \\
\hline Norway & & & LST1 & $\mathrm{T}$ & 0.22 & 0.25 & $0.83(0.60-1.15)$ & A & $2.60 \mathrm{E}-01$ \\
\hline Sweden & & & & $\mathrm{T}$ & 0.19 & 0.25 & $0.71(0.55-0.93)$ & A & 1.17E-02 \\
\hline
\end{tabular}

${ }^{\mathrm{a}}$ Localizations according to GRch37 (hg19) human genome build (as seen on UCSC genome browser http://genome.ucsc.edu) [28]. 
${ }^{\mathrm{b}} P$-values for associations resisting the 1000 permutations test are highlighted in bold.

The analysis is based on a total of 527 pSS patients and 532 controls. 
Table 3 Genotype association analysis

\begin{tabular}{|c|c|c|c|c|c|c|}
\hline \multirow[b]{2}{*}{ Marker } & \multicolumn{2}{|c|}{ Additive model } & \multicolumn{2}{|c|}{$\begin{array}{l}\text { Conditional regression - } \\
\text { rs1800629 }\end{array}$} & \multirow{2}{*}{$\begin{array}{l}\text { Dominant } \\
P \text {-values }\end{array}$} & \multirow{2}{*}{$\begin{array}{l}\text { Recessive } \\
P \text {-values }\end{array}$} \\
\hline & $P$-values & OR $(95 \% \mathrm{Cl})$ & $\begin{array}{l}P \text { - } \\
\text { values }\end{array}$ & OR $(95 \% \mathrm{CI})$ & & \\
\hline rs915654 & 1.53E-04 & $0.69(0.57-0.84)$ & 0.09 & $0.82(0.66-1.03)$ & $2.51 \mathrm{E}-04$ & $2.42 \mathrm{E}-02$ \\
\hline rs2844482 & $5.46 \mathrm{E}-03$ & $0.69(0.53-0.90)$ & 0.18 & $0.81(0.60-1.10)$ & $5.75 E-03$ & 3.75E-02 \\
\hline rs2239704 & 1.36E-02 & $0.79(0.66-0.95)$ & 0.75 & $0.96(0.77-1.20)$ & 3.33E-01 & 3.32E-04 \\
\hline rs909253 & 4.42E-08 & $1.65(1.37-1.98)$ & 0.03 & 1.32 (1.03-1.69) & $4.05 E-10$ & 3.63E-02 \\
\hline rs2229094 & 3.91E-04 & $0.69(0.56-0.85)$ & 0.12 & $0.83(0.65-1.05)$ & $3.60 \mathrm{E}-03$ & 3.47E-03 \\
\hline rs2229092 & 2.87E-01 & $0.82(0.56-1.19)$ & 0.78 & $0.94(0.62-1.43)$ & 4.04E-01 & 4.64E-02 \\
\hline rs1799964 & 8.80E-03 & $0.74(0.59-0.93)$ & 0.47 & $0.91(0.70-1.18)$ & $1.15 \mathrm{E}-02$ & $2.11 \mathrm{E}-01$ \\
\hline rs1800629 & $1.64 \mathrm{E}-11$ & $2.22(1.75-2.82)$ & & & $6.61 \mathrm{E}-11$ & $1.98 \mathrm{E}-03$ \\
\hline rs3093662 & 3.49E-01 & $0.82(0.54-1.24)$ & 0.87 & $0.96(0.61-1.52)$ & 4.25-E01 & $3.2 \mathrm{E}-01$ \\
\hline rs769178 & $9.10 \mathrm{E}-01$ & $0.98(0.66-1.45)$ & 0.90 & $1.03(0.66-1.61)$ & $9.01 \mathrm{E}-01$ & n.a. \\
\hline rs2256965 & $1.08 \mathrm{E}-03$ & $0.74(0.61-0.89)$ & 0.23 & 0.87 (0.70-1.09) & 7.11-E02 & $1.74 \mathrm{E}-04$ \\
\hline rs1052248 & 7.36E-03 & $0.76(0.62-0.93)$ & 0.32 & $0.88(0.70-1.13)$ & 2.78E-02 & 2.05E-02 \\
\hline
\end{tabular}


Table 4 Haplotype analyses. 2 - 3 sliding windows.

\begin{tabular}{|c|c|c|c|}
\hline & $\begin{array}{l}\text { Frequencies } \\
\text { Case - Controls }\end{array}$ & $\begin{array}{l}\text { Odds Ratio } \\
(95 \% \text { CI })\end{array}$ & $\begin{array}{l}\text { Regression } \\
\text { P-value }\end{array}$ \\
\hline \multicolumn{4}{|l|}{2 Markers Sliding Window Haplotypes } \\
\hline rs915654.A_rs2844482.G & $0.75 / 0.68$ & $1.47(1.21-1.77)$ & $1.30 \mathrm{E}-04$ \\
\hline rs2844482.G_rs2239704.C & $0.55 / 0.46$ & $1.44(1.22-1.72)$ & $8.28 \mathrm{E}-06$ \\
\hline rs2239704.C_rs909253G & $0.48 / 0.36$ & $1.61(1.36-1.92)$ & 2.42E-08 \\
\hline rs2239704.C_ rs909253.A & $0.19 / 0.25$ & $0.68(0.56-0.84)$ & $3.33 \mathrm{E}-04$ \\
\hline rs909253.G_rs2229094.A & $0.48 / 0.37$ & $1.59(1.34-1.89)$ & $5.79 \mathrm{E}-08$ \\
\hline rs909253.A_rs2229094.G & $0.18 / 0.25$ & $0.69(0.56-0.85)$ & $4.58 \mathrm{E}-04$ \\
\hline rs2229094.A_rs2229092.A & $0.81 / 0.75$ & $1.45(1.18-1.80)$ & $4.59 \mathrm{E}-04$ \\
\hline rs2229094.G_rs2229092.A & $0.13 / 0.19$ & $0.68(0.54-0.86)$ & $1.37 \mathrm{E}-03$ \\
\hline rs1799964.A_rs1800629.A & $0.31 / 0.19$ & $1.87(1.52-2.30)$ & $5.63 \mathrm{E}-14$ \\
\hline rs1800629.A_rs3093662.A & $0.31 / 0.18$ & $1.90(1.54-2.34)$ & $7.21 \mathrm{E}-15$ \\
\hline rs2256965.G_rs1052248.A & $0.48 / 0.37$ & $1.54(1.29-1.84)$ & $2.48 \mathrm{E}-07$ \\
\hline \multicolumn{4}{|l|}{3 Markers Sliding Window Haplotypes } \\
\hline rs915654.A_rs2844482.G_rs2239704.C & $0.43 / 0.31$ & $1.68(1.40-2.00)$ & $3.90 \mathrm{E}-10$ \\
\hline rs2844482.G_rs2239704.C_rs2239704.G & $0.48 / 0.36$ & $1.6(1.37-1.94)$ & 2.14E-08 \\
\hline rs2239704.C_rs909253.G_rs2229094.A & $0.49 / 0.37$ & $1.69(1.34-1.90)$ & $5.10 \mathrm{E}-08$ \\
\hline rs2239704.C_rs909253.A_rs2229094.G & $0.19 / 0.25$ & $0.69(0.56-0.86)$ & 5.33E-04 \\
\hline rs909253.G_rs2229094.A_rs2229092.A & $0.49 / 0.37$ & $1.59(1.34-1.89)$ & 5.79E-08 \\
\hline rs909253.A_rs2229094.G_rs2229092.A & $0.13 / 0.19$ & $0.68(0.54-0.86)$ & $1.37 \mathrm{E}-03$ \\
\hline rs2229094.A_rs2229092.A_rs1799964.A & $0.81 / 0.75$ & $1.45(1.18-1.79)$ & $4.59 \mathrm{E}-04$ \\
\hline rs2229092.A_rs1799964.A_rs1800629.A & $0.31 / 0.19$ & $1.87(1.52-2.29)$ & $5.65 \mathrm{E}-14$ \\
\hline rs1799964.A_rs1800629.A_rs769178.A & $0.31 / 0.18$ & $1.87(1.52-2.30)$ & $4.89 \mathrm{E}-14$ \\
\hline rs1800629.A_rs769178.A_rs2256965.C & $0.30 / 0.17$ & $1.87(1.51-2.31)$ & $4.83 \mathrm{E}-14$ \\
\hline rs769178.A_rs2256965.C_rs1052248.A & $0.46 / 0.36$ & $1.52(1.27-1.81)$ & $1.52 \mathrm{E}-06$ \\
\hline rs2256965.G_rs1052248.A & $0.48 / 0.37$ & $1.54(1.30-1.83)$ & $2.48 \mathrm{E}-07$ \\
\hline \multicolumn{4}{|l|}{ rs909253_rs1800629 } \\
\hline rs909253.G_rs1800629.A & $0.29 / 0.15$ & $2.14(1.72-2.65)$ & $9.14 \mathrm{E}-17$ \\
\hline
\end{tabular}


Table 5 Association analysis of the 12 SNPs in the TNF/LTA locus in antibody positive ${ }^{a}$ pSS patients versus controls and antibody positive ${ }^{\mathrm{a}}$ pSS patients versus antibody negative pSS patients.

\begin{tabular}{|c|c|c|c|c|c|c|c|c|}
\hline \multirow[b]{2}{*}{ SNP } & \multirow[b]{2}{*}{$\begin{array}{l}\text { Minor } \\
\text { allele }^{\text {b }}\end{array}$} & \multicolumn{2}{|c|}{ Minor allele frequency } & \multirow[b]{2}{*}{$P$-value ${ }^{c}$} & \multirow[b]{2}{*}{ OR $(95 \% \mathrm{Cl})^{\mathrm{c}}$} & \multicolumn{2}{|c|}{ Minor allele frequency } & \multirow[b]{2}{*}{ OR $(95 \% \mathrm{CI})^{\mathrm{d}}$} \\
\hline & & $\begin{array}{l}\text { Ab positive } \\
\mathrm{n}=381\end{array}$ & $\begin{array}{l}\text { Controls } \\
n=532\end{array}$ & & & $\begin{array}{l}\text { Ab negative } \\
n=138\end{array}$ & $P$-value ${ }^{\mathrm{d}}$ & \\
\hline rs915654 & $\mathrm{T}$ & 0.20 & 0.32 & $1.42 \mathrm{E}-08$ & $0.53(0.42-0.67)$ & 0.36 & $1.35 E-06$ & $0.47(0.34-0.64)$ \\
\hline rs2844482 & $A$ & 0.09 & 0.15 & $6.14 \mathrm{E}-05$ & $0.54(0.4-0.74)$ & 0.17 & 5.08E.04 & $0.47(0.31-0.72)$ \\
\hline rs2239704 & A & 0.32 & 0.37 & $1.49 \mathrm{E}-02$ & $0.78(0.64-0.95)$ & 0.33 & 8.53E-01 & $0.97(0.7-1.34)$ \\
\hline rs909253 & G & 0.52 & 0.37 & $1.14 \mathrm{E}-10$ & $1.9(1.56-2.33)$ & 0.40 & $1.88 \mathrm{E}-04$ & $1.79(1.31-2.45)$ \\
\hline rs2229094 & $\mathrm{G}$ & 0.16 & 0.25 & 2.37E-06 & $0.57(0.45-0.72)$ & 0.26 & $1.48 \mathrm{E}-04$ & $0.51(0.36-0.72)$ \\
\hline rs2229092 & C & 0.04 & 0.06 & 4.32E-02 & $0.64(0.41-1.00)$ & 0.08 & 1.65E-02 & $0.47(0.26-0.86)$ \\
\hline rs1799964 & $\mathrm{G}$ & 0.13 & 0.20 & 1.97E-04 & $0.61(0.47-0.8)$ & 0.22 & $1.15 \mathrm{E}-03$ & $0.54(0.38-0.78)$ \\
\hline rs1800629 & A & 0.39 & 0.20 & $3.78 \mathrm{E}-18$ & $3.09(2.36-4.04)$ & 0.19 & $1.52 \mathrm{E}-10$ & $3.39(2.27-5.05)$ \\
\hline rs3093662 & $\mathrm{G}$ & 0.04 & 0.05 & 3.26E-01 & $0.80(0.5-1.26)$ & 0.05 & $3.65 E-01$ & $0.75(0.41-1.37)$ \\
\hline rs769178 & A & 0.05 & 0.06 & $5.66 \mathrm{E}-01$ & $0.88(0.56-1.37)$ & 0.07 & $1.36 \mathrm{E}-01$ & $0.63(0.34-1.14)$ \\
\hline rs2256965 & A & 0.33 & 0.40 & $1.05 \mathrm{E}-03$ & $0.71(0.58-0.87)$ & 0.37 & $3.12 \mathrm{E}-01$ & $0.85(0.62-1.16)$ \\
\hline rs1052248 & $\mathrm{T}$ & 0.18 & 0.25 & 3.92E-04 & $0.66(0.52-0.83)$ & 0.25 & 1.75E.02 & $0.66(0.47-0.93)$ \\
\hline
\end{tabular}

${ }^{\mathrm{a}} \mathrm{Anti-Ro/SSA}$ positive or anti-Ro/SSA-La/SSB positive patients. Data was not available from eight patients.

${ }^{\mathrm{b}}$ Minor allele based on all patients, positive and negative.

${ }^{\mathrm{c}} P$-value, odds ratio $(\mathrm{OR})$ and $95 \%$ confidence interval $(\mathrm{Cl})$ for differences in allele frequencies between $\mathrm{Ab}$ positive patients and controls.

${ }^{d} P$-value, odds ratio (OR) and $95 \%$ confidence interval $(\mathrm{Cl})$ for differences in allele frequencies between $\mathrm{Ab}$ positive patients and Ab negative patients. Association analysis was performed using a logistic regression on genotypes coded after additive model (see Table 4) and using sex and kohort as covariate.

Significant $P$-values are highlighted in bold. 


\section{Supplementary material}

Table 1S Prevalence of extraglandular manifestations in pSS patients.

\begin{tabular}{|c|c|c|c|c|c|c|}
\hline $\begin{array}{l}\text { Category } \\
\text { Extraglandular manifestation }\end{array}$ & \multicolumn{2}{|l|}{$\begin{array}{l}\text { Sweden } \\
\mathrm{n}=334\end{array}$} & \multicolumn{2}{|l|}{$\begin{array}{l}\text { Norway } \\
n=193\end{array}$} & \multicolumn{2}{|c|}{$\begin{array}{l}\text { Sweden and Norway } \\
\mathrm{n}=527\end{array}$} \\
\hline Arthritis & $60 / 334$ & $18.0 \%$ & $35 / 193$ & $18.1 \%$ & $95 / 527$ & $18.0 \%$ \\
\hline Dermal vasculitis & $52 / 334$ & $15.6 \%$ & $10 / 193$ & $5.2 \%$ & $62 / 527$ & $11.8 \%$ \\
\hline Hypothyroidism $^{\text {a }}$ & $46 / 238$ & $19.3 \%$ & $54 / 193$ & $28.0 \%$ & $100 / 431$ & $23.2 \%$ \\
\hline Raynaud's phenomenon ${ }^{a}$ & $92 / 333$ & $27.6 \%$ & 73/193 & $37.8 \%$ & $165 / 526$ & $31.4 \%$ \\
\hline P- $\operatorname{lgG}>15 \mathrm{~g} / \mathrm{L}^{\mathrm{a}}$ & $160 / 280$ & $57.1 \%$ & $73 / 181$ & $40.3 \%$ & $233 / 461$ & $50.5 \%$ \\
\hline Leucopenia $<4 \times 10^{9} / \mathrm{L}^{\mathrm{a}}$ & $96 / 306$ & $31.4 \%$ & $55 / 193$ & $28.5 \%$ & $151 / 499$ & $30.3 \%$ \\
\hline Lymphadenopathy $^{a}$ & $36 / 323$ & $11.1 \%$ & $13 / 193$ & $6.7 \%$ & $49 / 516$ & $9.5 \%$ \\
\hline Lymphoma $^{a}$ & $16 / 333$ & $4.8 \%$ & $4 / 193$ & $2.1 \%$ & $20 / 526$ & $3.8 \%$ \\
\hline Major salivary gland swelling ${ }^{a}$ & $114 / 331$ & $34.4 \%$ & $58 / 128$ & $45.3 \%$ & $172 / 459$ & $37.5 \%$ \\
\hline
\end{tabular}

${ }^{a}$ Data were not available in all patients. 